\title{
AS REVISTAS, SEU PÚBLICO E A MODERNIZAÇÃO DA CIDADE $^{1}$
}

\author{
Vera Regina Martins Collaço (orientadora) \\ Rosane Faraco Santolin (bolsista) ${ }^{2}$
}

\begin{abstract}
RESUMO: A década de 1920 é um período de auge do Teatro de Revista em todo o Brasil e os intelectuais catarinenses também se interessaram pelo gênero, fazendo produções e recebendo companhias vindas de outras localidades brasileiras. Dentro deste panorama, algumas produções apresentaram maior ou menor aceitabilidade, segundo critérios de público e de costumes ilhéus do período. Essa fase é significativa em mudanças nos aspectos urbanos e sociais de Florianópolis, e essas transformações repercutiram na produção revisteira local.
\end{abstract}

PALAVRAS-CHAVE: Teatro de revista, Imprensa, Recepção

"Salve, Ilha, toda cheia De encantos taes e tão caros!",3

O Teatro de Revista é um espetáculo ligeiro, do gênero do teatro musicado, que passa em revisão os acontecimentos da atualidade de forma cômica. A revista busca atingir o maior número possível e diferenciado de público, tendo, em suas origens, forte denotação crítica e política; a revista ri de si mesma e dos fatos oriundos do seu meio e da sociedade. Esse é um dos elementos mais importantes da revista e por isso ela se torna tão rica, já que, ao contemplar o seu público com o riso perante o que ele próprio vivencia, ela também é fonte de pesquisa do seu contexto político, artístico e social.

A força da atividade revisteira no Brasil se deu na primeira metade do século XX na então capital federal, Rio de Janeiro, e também em São Paulo, sendo que em cada região acresciam particularidades locais - fator inerente à revista, em virtude de representar a sua realidade -, mas em todas apresentando uma estrutura básica comum. Porque a revista, que deixava entrar de quase tudo um pouco, tinha convenções muito

\footnotetext{
${ }^{1}$ Projeto de Pesquisa "O teatro de revista seduz a elite de Florianópolis na década de 1920", orientadora Prof $^{a}$ Dr $^{a}$ Vera Regina Martins Collaço, Departamento de Artes Cênicas da Universidade do Estado de Santa Catarina, UDESC.

${ }^{2}$ Bolsista PROBIC, acadêmica do curso de Licenciatura em Artes Cênicas da Universidade do Estado de Santa Catarina, UDESC.

${ }^{3}$ Nicolau Nagib Nahas, A Ilha dos Casos Raros, 1927. Observamos que reproduzimos a ortografia e linguajar das personagens e cenas tal qual se encontra no texto analisado e nos jornais pesquisados.
} 
bem estabelecidas; muita coisa podia entrar na revista, mas a revista não se enquadrava dentro de "qualquer coisa".

Além da capital federal e da estreante a cidade grande, ou seja, São Paulo, outras regiões brasileiras também desejavam partilhar dessa diversão, como observa Neyde Veneziano (1991:44):

[A revista] se alastrava por todo o país. Pelas capitais e pelo interior. Cidades pequenas, sem esgoto, sem luz elétrica, orgulhavam-se de possuir um teatro que recebia as sempre bem-vindas companhias de teatro de revista. Havia várias delas, companhias errantes, viajando por estradas de ferro e levando o mundo alegre e colorido da revista aos cantos mais distantes.

Santa Catarina, e no caso de nosso objeto de estudo, a cidade de Florianópolis, não poderia ficar de fora dessa leva revisteira. A Ilha também recebeu várias dessas companhias que atravessavam o país para levar o riso e a galhofa das revistas. Porém, brincando com a fala de Neyde Veneziano acima colocada, aqui chegavam, no decorrer da década de 1920, não de trem, mas de vapor - navio, pois Florianópolis até 1926 era isolada por via terrestre do resto do país.

Ainda com palavras de Neyde Veneziano (1991:45), ressaltamos mais um aspecto efervescente da revista brasileira no período aqui analisado, a década de 1920, o qual não eram apenas as pequenas companhias que punham o pé na estrada, ou adentravam o mar num navio: "também viajavam as grandes companhias do Rio de Janeiro. Era a Praça Tiradentes chegando a outros estados e estes outros estados também produzindo as suas próprias revistas com características próprias”. De fato isso se deu também em Florianópolis e em outras cidades do estado de Santa Catarina, como, por exemplo, em Lages, conforme nossa pesquisa já pôde apurar. A década de 1920, especialmente os primeiros anos, foi relativamente rica em produção de revistas por autores ilhéus, e salientamos que quase todas passaram pelo crivo do palco, de acordo com as notas publicadas pela imprensa local, e a obra Se a Moda Pega (2007), que aborda esta questão e outras pertinentes ao teatro de revista em Florianópolis.

Ao partir da percepção que os espetáculos revisteiros percorriam as diferentes cidades brasileiras e que estas cidades, a partir deste envolvimento, também produziam as suas revistas, direcionamos o foco deste estudo para a recepção destes trabalhos. Assim, neste artigo procuramos trazer à tona a problemática sobre a recepção ao teatro 
revisteiro na Ilha. Para isso, dada a disponibilidade das fontes, pretendemos realizar uma análise sobre a repercussão das revistas produzidas pelos amadores florianopolitanos na década de 1920, bem como sobre as companhias vindas de outras localidades brasileiras e que apresentaram revistas na cidade.

Para desenvolver este trabalho contamos com matérias coletadas nos jornais locais da década de 1920, três peças escritas por revisteiros da Ilha e estudos teóricos empreendidos pelos historiadores e pesquisadores de Santa Catarina. Este último material serve para contextualização, pano de fundo, assim como para encontrar algo mais próximo da revista, ou seja, o dia-a-dia, os costumes, o cotidiano de Florianópolis deste período. Contudo, a principal fonte de informações deste estudo são os registros encontrados na imprensa local, e é desta forma que tentamos estabelecer as relações e influências desse meio predominante de comunicação com os espectadores, percebendo o jornal - o crítico - como um "representante da opinião do público" e que assim emite sua opinião, mas procura também influenciá-lo e instigá-lo à ida ao teatro. É notório o papel do jornal tanto na divulgação das revistas e companhias, como nos seus comentários e reflexões acerca do que era visto e do que se pretendia querer ser visto.

\section{Ouverture}

Na década de 1920, Florianópolis era uma cidade pequena, com uma população de 41.388 habitantes $^{4}$, com características de província e bastante isolada. A ponte Hercílio Luz, a primeira a conectar a Ilha ao continente, só foi construída ao final dessa década, e as estradas eram, e ainda o são, extremamente precárias. Até a construção da ponte a travessia ilha-continente, e vice-versa, era feita somente de barco, envolvendo todas as dificuldades e riscos em função dos ventos, que este transporte oferecia. Além de isolada, a Ilha também era uma cidade sem grandes recursos financeiros e industriais, mas que se desejava modernizar, com sonhos europeus vislumbrados e almejados pela elite florianopolitana.

Esses fatores, contudo, não impediram que a capital catarinense desenvolvesse suas atividades teatrais nem que companhias pudessem visitá-la, mas tornavam a circulação escassa e reservada praticamente a alguns modelos de revista. As companhias que aqui se apresentavam procediam, em sua maioria, de São Paulo, mas também

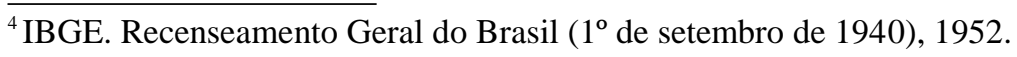


vinham companhias de outros estados, do Rio Grande do Sul e do Rio de Janeiro. A cidade não serviu de espaço para a apresentação das grandes companhias de revistas cariocas. Na Ilha não estiveram vedetes deslumbrantes como Otília Amorim, Lia Binatti, Aracy Cortes, Margarida Max, Lódia Silva e outras; mas, por aqui passaram, numa linha caricata e menos sensual Alda Garrido, Pepita de Abreu e cômicos de primeira linha como Olímpio Bastos (o Mesquitinha), Manoel Pêra e outros.

O que teria levado, além do fator econômico e limitante da própria cidade, à vinda de mais companhias paulistas do que cariocas à Florianópolis? Acreditamos que essa problemática deve ser compreendida dentro da própria concepção da revista paulista, na diferenciação entre a revista paulista e a carioca e, também, na percepção que, na década de 1920, São Paulo, embora já dando encaminhamentos para a futura cidade industrial e rica, ainda continha muitos aspectos provincianos e vinculados ao mundo rural. Neste sentido podemos perceber uma aproximação temática entre a revista paulista e a florianopolitana. O provincianismo nos aproximava, e, como conseqüência, certo moralismo imperante na revista paulista encontrava ressonância e aceitação no público ilhéu, que sempre percebia a revista carioca como sensual e "picante" para o paladar florianopolitano.

Nesse quadro, é necessário levar em conta a questão da valorização do homem rural, sertanejo, tendo, desse modo, suas raízes genuinamente nacionais, e que circundava a manifestação paulista e ia ao encontro do pensamento e estilo de vida dos florianopolitanos. Pois, ao contrário da revista carioca, que aspirava à boemia e à malícia sexual, com os tão utilizados doublé-sens ${ }^{5}$, a revista paulista apoiou-se por muito tempo nos regionalismos, na imagem do caipira, com linguajar mais ingênuo; aqui, a comicidade estava mais centrada na estrutura do homem-trabalhador, do homem rural.

\section{E a festa começa...}

O palco se abre para os intelectuais florianopolitanos com a revista de Clementino de Brito, Casa de Brinquedos, seguida de Jardim Maravilhoso, do mesmo autor, que alcançou grande êxito: "o panno desceu debaixo de acclamações delirantes,

\footnotetext{
${ }^{5}$ Double-sens são os duplo-sentidos muito utilizados dentro da linguagem revisteira, geralmente com conotação sexual.
} 
subindo, á insistentes pedidos da assitencia para que viessem à scena os autores da bella peça, que receberam carinhosa e enthusiastica manifestação". ${ }^{6}$ Apesar de não seguir à risca a estrutura de uma revista, Jardim Maravilhoso definitivamente abriu espaço e entusiasmo para os intelectuais ilhéus, que viam agora as possibilidades de chegarem ao público através do palco. Como bem observava Sachet (1975:137) numa referência à dificuldade dos escritores ilhéus,

Não lhe bastavam mais as passageiras colunas dos empanturrados em publicidade - O Estado e República, ávidos em digerirem contos, poesias e artigos de crítica, ao lado de "A Saúde da Mulher", do sabonete Dorly e das Pílulas de Reuter, Com uma desvantagem: enquanto os remédios e os sabonetes, voltavam no jornal no dia seguinte, a produção do intelectual, a ele não retornaria nunca mais.

A elite intelectual florianopolitana, portanto, impossibilitada de publicar seus próprios livros, devida à dificuldade de edição, vê no sucesso da revista de Clementino de Britto o impulso para começar suas próprias produções. $\mathrm{O}$ fato se evidencia com a sucessão de revistas que são escritas e encenadas nos primeiros anos da década de 1920 por diferentes autores. Gustavo Neves, redator do jornal $O$ Estado, acadêmico e cronista, escreveu no jornal sobre a utilidade dessa nova produção teatral em Florianópolis e em Santa Catarina, observando que, "ninguém, lá fora, sabe o que é a leitura catharinense", e que o teatro seria uma ótima forma de "ao menos os viajantes que por aqui passarem dizerem lá fora que o que nos está faltando é só uma casa editora; porque capacidade para produzir nós a temos". ${ }^{7}$ Gustavo Neves, cheio de entusiasmo, afirmou, no jornal $O$ Estado de 19 de setembro de 1921, com veemência o nascer do teatro catarinense: "é já um facto. A actividade intellectual da terra barriga-verde é, em grande parte, para elle [teatro]. E essa grande parte já tende a augmentar”.

Apesar dessa crescente produção, é importante ressaltar que o desempenho destas revistas estava ao encargo de jovens atores e atrizes, oriundos da elite econômica da cidade, - ou no máximo aos intelectuais envolvidos nas produções, que também poderiam atuar em suas próprias revistas ou em revistas de outros colegas - os quais não poderiam aventurar-se além do que seu porte de "pessoas de família" lhes permitia. E este cuidado não passava despercebido da imprensa local:

${ }^{6}$ O ESTADO, Florianópolis, 22 de outubro de 1920

${ }^{7}$ O ESTADO, Florianópolis, 19 de setembro de 1921 
Talvez um chronista mais exigente desejasse ver da parte dos interpretes maior desembaraço, mais "élan", em summa, em certas situações que não podem ser preconceitos sociais... Ponderar-lheíamos nós que os amadores, que hontem entraram em scena, fazem bem, como filhos de família que são, em manter uma linha discreta, digamos mesmo um recato que somente pode vir em abano das suas louváveis virtudes. ${ }^{8}$

Desculpas - amplamente justificadas - eram dadas aos atores amadores da revista florianopolitana - "a interpretação, afora alguns senões dispensáveis em amadores, agradou extraordinariamente", 9 - já que aqui não tínhamos artistas profissionais, e, como a elite não queria ultrapassar normas de conduta as quais se queria ensinar e manter, o trabalho do palco baseou-se mais em pequenos gracejos ingênuos, trocadilhos engraçados, mas sem o chiste, o glamour das vedetes e a irreverência dos cômicos.

Mas é inegável, com mais ou menos malícia, dentro ou não de um padrão de costumes, fez-se revista em Florianópolis assim como no Brasil e no mundo. A esse respeito se posiciona Gustavo Neves: a revista é um "gênero de theatro que deleita vinte e cinco milhões de brasileiros, incluídas as crianças de dois annos, que jà sabem rir com a necessaria malicia, e os velhos de sessenta e mais, que ainda conservam alguma coisa da mocidade". ${ }^{10}$

\section{Da moral e bons costumes}

Tanto das companhias que vinham de fora quanto das produções locais, o que mais era levado em conta, no que concerne aos aspectos temáticos das representações, era como a revista se apresentava em maior ou menor grau de moralidade. Conforme já mencionamos, Florianópolis conservava valores provincianos que em muito se adequavam ao estilo da revista paulista. Os espetáculos deveriam ser, sobretudo, de cunho familiar. Sobre a revista Seu Jeca qué casá, de Mâncio Costa, pode-se destacar o seguinte comentário da imprensa local que reforça nossa colocação:

\footnotetext{
${ }^{8}$ O ESTADO, Florianópolis, 14 de setembro de 1923

${ }^{9}$ A VERDADE, Florianópolis, 15 de novembro de 1921

${ }^{10}$ Gustavo Neves, in: $O$ ESTADO, Florianópolis, 19 de setembro de 1921
} 
Houve muita felicidade na escolha do motivo, ou melhor, os seus autores tiveram a clara e perfeita compreensão de que à nossa platéa só podem agradar as peças que fazem rir sem corar e que dão momentos de alegria sã.

Temos já que é tempo de se por paradeiro às grosserias e aos descalabros de certas companhias de verdadeiros cavadores.

Porque a verdade é que o nosso theatro tem sido uma fonte de renda para certos artistas que viajam e trabalham premidos por apertos financeiros.

D'ahi a sua sede de nomeada, generadadora de concorrência, e d'ahi as patifarias em peças apresentadas, as imoralidades e asneiras que se fazem ouvir da ribalta. ${ }^{11}$

Portanto, ao revisteiro local o melhor caminho a seguir era o de afastar-se das "imoralidades e patifarias" colocadas em cena por companhias que se encontravam no limite econômico e onde o decoro fugiu para outras paragens. A mesma exaltação se fez presente quando da produção da revista local Não se Mexa, de Clementino Britto: “É escripta nos moldes do theatro moderno, em estylo leve e delicado, revestindo-se, apesar de francamente hilariante, da mais absoluta moralidade". ${ }^{12}$ As revistas deveriam, portanto, para o público ilhéu - ou pela perspectiva da imprensa local - serem providas de boa música, de situações cômicas e alegria, mas tudo, tudo dentro da mais completa moralidade. Sem malícia, sem rebolado.

Outro aspecto também entrava na avaliação - especialmente dos articulistas em relação ao sucesso e apreço de uma revista: a questão moral ao redor da crítica. Os jornais divulgavam quase sempre de forma positiva as produções de seus conterrâneos o enaltecimento dessas produções se devia também ao fato de muitos destes revisteiros serem articulistas da imprensa local, atuarem como redatores, colaboradores eventuais, etc. Mas, esse elemento facilitador com que divulgavam seu trabalho, desde os primeiros ensaios até a estréia, não impedia algumas críticas, especialmente quando o autor avançava além do permissível e permitido pela moral local. Os articulistas da imprensa local assumiam ares de verbalizar o gosto e o querer do público, ou seja, eles representavam a opinião pública. E desta forma muitas vezes cabia a eles estimular aos autores a produzirem ou a diminuir seu apetite pela crítica mordaz ou sensual. Este foi o caso da revista Ilha dos Casos Raros, de Nicolau Nagib Nahas, apresentada à numerosa platéia, e onde alguns trechos possuíam “críticas demasiadamente fortes”, no sentido de

\footnotetext{
${ }^{11}$ REPÚBLICA, Florianópolis, 25 de junho de 1921

${ }^{12}$ REPÚBLICA, Florianópolis, 19 de fevereiro de 1927
} 
serem "muito pessoais". ${ }^{13}$ A imprensa local não perdoou e fez valer a sua voz de representante: "Sabemos que o autor, levando em consideração observações nossas e de outras pessoas, resolveu substituir, por outros números, algumas críticas, um tanto pesadas, que impediam um maior sucesso da peça". ${ }^{14}$

\section{Quadro fantasia - as mudanças em prol do "embelezamento" da Ilha}

O período do final do século XIX em Florianópolis, até a terceira década do século XX, apresenta-se como bastante produtivo intelectualmente, ao lado da modificação do panorama urbano rumo à sonhada modernização, onde houve a “preocupação do delineamento da definição da estrutura cultural em Santa Catarina a partir da sua capital”. (CORRÊA, 2004:300). É certo que Florianópolis precisava de remodelações e sua população necessitava de novas instruções quanto à higiene e cuidados básicos que aos poucos se faziam mais conhecidos pela medicina. Entretanto, as vias em que um ponto chega ao outro estavam estreitamente ligadas aos interesses da elite econômica florianopolitana. Outrossim, a questão da higiene era vista como uma forma de proteger esta elite das doenças que a classe desfavorecida poderia oferecer.

Primeiramente, uma capital não poderia ser tão pobre e ter aparência deveras nauseante e desagradável. Era preciso, assim, embelezar a capital, construir novas edificações, iluminar suas ruas, dar-lhe um ar de urbanidade e salubridade. Entretanto, para tal feito, diversas casas da região central foram destruídas - o prédio do Congresso Representativo ou o Teatro Álvaro de Carvalho não poderiam ter como vizinhos casebres pobres e sujos - e seus moradores foram obrigados a se recolherem para os morros. É o início da periferização da cidade. Não estava se construindo apenas uma cidade mais bonita, mas estava-se escondendo tudo o que era feio. E esse povo, cheio de maus hábitos, continuaram nas mesmas condições, porém afastados.

O trabalho contínuo, assíduo e remunerado, na fase dos serviços prestados, considerado a legítima forma de sobrevivência e de utilização produtiva do tempo, passou a ser um dos aspectos defendidos e disseminados através de discursos e investimentos disciplinares sobre a população. (NECKEL, 2003:63)

\footnotetext{
${ }^{13}$ REPÚBLICA, Florianópolis, 13 de setembro de 1927

${ }^{14}$ REPÚBLICA, Florianópolis, 7 de setembro de 1927
} 
O trabalho que não estivesse enquadrado dentro desse sistema, como os pescadores e vendedores ambulantes, começaram a ser discriminados, e práticas que não fossem ao encontro da produtividade trabalhista foram condenadas. Exaltava-se, com ênfase cada vez maior, o valor do trabalho e da família. O instrumento predominante de propagação desses valores foi, sem dúvida, o maior meio de comunicação da época, o jornal. E na visão da intelectualidade ilhoa, ao teatro deveria caber outra grande parcela da responsabilidade na divulgação dos valores "saudáveis" para a nossa sociedade.

Dentro desse panorama de modernização e reformulações, o teatro, a revista, junto com o jornal, também foi meio de propagação de valores, de costumes; apontava condutas, e para isso utilizava-se de alegorias e convenções. Apesar dos intelectuais ilhéus estarem diretamente ligados à questão política, eles utilizaram o teatro, através das revistas, não apenas para afirmar essas questões, mas também para questionar e criticar o que acontecia a sua volta.

\section{Pelos caminhos do hoje e do amanhã}

Por ora, o que queríamos buscar com esta pesquisa foi como o público de Florianópolis envolveu-se com o teatro de revista. A fonte documental para este resgate histórico restringiu-se, na sua maior parte, aos periódicos locais da década de 1920. O nosso intuito foi apresentar uma discussão sobre a recepção aos espetáculos de revistas realizados pelos amadores da cidade e à recepção às companhias de revistas de outros estados que se apresentavam em Florianópolis. Estivemos cientes dos limites de material para debater a problemática da recepção ao teatro revisteiro. Mas, acreditamos que os jornais nos permitiram perceber, pelo menos, como a imprensa local percebia esta produção e como se posicionava em relação ao teatro de revista local e ao que se apresentava na cidade, vindo de outras paragens.

Através dos comentários expostos nos jornais locais podemos também auferir a presença ou não de público às representações, tanto locais quanto de fora da cidade. E o que pudemos perceber foi à constante presença de grande público aos espetáculos de revista, fossem estes locais ou não. Resulta, quase sempre, elogiosa as notas 
jornalísticas com relação ao público presente aos espetáculos revisteiros, a não ser quando a companhia passava o limite da tolerância local.

No prosseguimento desta pesquisa devemos nos voltar para a análise das revistas produzidas pela intelectualidade local e continuar insistindo no estudo sobre a recepção deste trabalho junto à sociedade catarinense.

\section{Referências Bibliográficas}

COLLAÇO, Vera. Se a moda pega: o teatro de revista em Florianópolis 1920/1930. Florianópolis: Ed. da UDESC, 2007.

CORREA, Carlos Humberto. História de Florianópolis Ilustrada. Florianópolis: Insular, 2004.

GOMES, Tiago de Melo. Um espelho no palco - identidades sociais e massificação da cultura no teatro de revista dos anos 1920. Campinas: Editora da Unicamp, 2004. INSTITUTO BRASILEIRO DE GEOGRAFIA E ESTATÍSTICA. Recenseamento Geral do Brasil (1º de setembro de 1940). Série Regional. Parte XIX. Santa Catarina. Censo Demográfico. População e Habitação. Censos Econômicos, Agrícola, Industrial, Comercial e dos Serviços. Rio de Janeiro: Serviço Gráfico do IBGE, 1952. NECKEL, Roselane. A República em Santa Catarina: modernidade e exclusão (1889 - 1920). Florianópolis: Ed. da UFSC, 2003.

PAIVA, Salvyano Cavalcanti de. Viva o rebolado! - Vida e morte do teatro de revista brasileiro. Rio de Janeiro: Nova Fronteira, 1991.

SACHET, Celestino. As transformações estético-literárias dos anos 20 em Santa Catarina. Florianópolis: UDESC/DAPE: EDEME, 1974.

VENEZIANO, Neyde. De pernas para o ar: Teatro de revista em São Paulo. São Paulo: Imprensa Oficial, 2006.

Campinas: Ed. da UNICAMP, 1996.

Não adianta chorar: teatro de revista brasileiro... Oba!.

O teatro de revista no Brasil: dramaturgia e convenções.

Campinas: Ed. da UNICAMP, 1991.

A VERDADE, Florianópolis, 15 de novembro de 1921

$O$ ESTADO, Florianópolis, 14 de setembro de 1923

O ESTADO, Florianópolis, 22 de outubro de 1920

O ESTADO, Florianópolis, 19 de setembro de 1921

REPÚBLICA, Florianópolis, 25 de junho de 1921.

REPÚBLICA, Florianópolis, 19 de fevereiro de 1927

REPÚBLICA, Florianópolis, 7 de setembro de 1927

REPÚBLICA, Florianópolis, 13 de setembro de 1927 